\title{
Theoretical Exploration and Practice Path on Hotel Management Curriculum Group
}

\author{
Jiajing $\mathrm{HU}^{*}$ \\ School of tourism management \\ Sichuan Agricultural University \\ Dujiangyan, China \\ jiajing111@sina.com
}

\author{
Qian GOU \\ Department of economics management \\ Dazhou vocational and technical college \\ Dazhou, China \\ Gouqian_620@hotmail.com
}

\begin{abstract}
This paper describes the background of curriculum reform and discusses some related theoretical and practical issues of hotel curriculum group. Using detail analysis from the theoretical and practical point of view, this paper report here that the establishment of the hotel management curriculum group not only adapts to the characteristics of cross-subject, but also meets the goal of cultivating the hotel management talents, and can effectively overcome the current teaching shortcomings of hotel management. And reconstructing curriculum content, cultivating a curriculum team with cross-subject teaching quality, and guiding students to establish a learning mode that contains both learning and thinking are the construction paths for the hotel management curriculum group.
\end{abstract}

Keywords—curriculum group; hotel management; co-evolution; practice path

\section{INTRODUCTION}

For the purpose of cultivating specialized talents, subject-oriented education that emphasizes the knowledge system within the subject is the basic concept of management in higher education in China. However, with the transformation of cultivating talents from "specialized talents" to "general talents", the professionals trained in the traditional sub-branch education system are not able to meet the needs of economic and social development in the new situation. To break through the inherent knowledge boundaries of different curricula and integrate individual curriculum with other curricula to form a series of linked curriculum groups with reasonable structure, clear levels, and mutual connection, cooperation and interaction among curricula. In order to teach comprehensive management knowledge and cultivate managers who master diverse knowledge effectively, teachers should break through the inherent knowledge boundaries of different curricula and integrate individual curriculum with other curricula to form a series of linked curriculum groups with reasonable structures, clear levels, and mutual connection, cooperation and interaction among curricula ${ }^{[1]}$.

The teaching content and objectives of hotel management include: analyze and solve functional management issues, such as hotel industry background and brand expansion, hotel business decisions and operation, hotel financial analysis and cost control, human resources optimization, marketing channel development and pricing. These contents and objectives are often fragmented in the traditional curriculum system and discussed in different curricula which is difficult to promote students to form a systematic and correlated thinking in the issues above. However, the construction of curriculum group can effectively avoid the shortcomings of traditional curriculum system. For this reason, the essay has analyzed the meaning function, theoretical feasibility, purpose and urgency of the hotel management curriculum group, and explores the construction path of the hotel management curriculum group from a practical perspective in order to provide suggestions for the construction of the curriculum group.

\section{The Meaning and Function of CuRriculum Group}

\section{A. The Meaning of Curriculum Group}

In the process of curriculum construction, teachers are only focusing on the design of single curriculum and ignoring the relevance between different curricula which can easily lead to some problems, such as imbalance courses, unreasonable convergence or repetition of content between curricula. The curriculum group is guided by modern education thoughts and theories, and aims at cultivating the talents of the same major or different majors, so as to improve the structure of knowledge, ability, and quality of the corresponding professional students that several curricula with logical connections in the knowledge, methods, and questions in the corresponding professional training programs are re-planned and integrated into an organic curriculum system. ${ }^{[2]}$ In the education of management, curriculum group construction aims at horizontal and related integration of related and similar subject, and enables students to apply multidisciplinary knowledge, theories and methods to solve major theoretical or practical problems so as to cultivate students' comprehensive management capabilities..

\section{B. The function of curriculum group}

Firstly, the construction of curriculum group can help integrate fragmented knowledge into systematic content. Nowadays, the related curricula in hotel management which are divided in accordance with the subjects are all built within an independent knowledge framework. They emphasize the integrity of the internal knowledge system in different curricula, while ignore the effective link of knowledge between subjects and subjects, curricula and curricula ${ }^{[3]}$, which is not conducive to different subjects and different curricula in the relevant concepts, knowledge content, management methods and other aspects of effective 
interaction and integration so that the knowledge granted to students is fragmented, rather than a system of knowledge. The construction of curriculum group emphasizes the horizontal knowledge system that connects and interacts in different fields, which integrate the theories, methods or paradigms of different subjects and different curricula organically to encourage students to follow the example by analogy, and to develop students' comprehensive management capabilities in the face of complex situations and complex problems in hotel operations.

Secondly, the construction of the curriculum group can help break down the solidified teaching activities. At present, the division and setting of departments or teaching and research sections on the basis of subjects is the main method of organization in universities in China ${ }^{[4]}$. The research activities and teaching activities of the hotel management curricula are run independently with each other which is difficult for teachers in solidified teaching activities to participate in the collision and integration of knowledge. Hence, the construction of the curriculum group can break the boundaries of the original curriculum and conducts extensive exchanges and discussions between subjects when designing the curriculum. The teachers from different subject backgrounds are invited to participate in the curriculum teaching, which can lead students in a comprehensive, mufti angle analysis of a management problem, listen to the voices and perspectives of teachers from different subjects background, promote dynamic interaction between subjects, accelerate the integration of knowledge between subjects.

Last but not least, the construction of curriculum group can help change the student roles. Although the previous hotel management education focused on students' participation in the classroom, and students' roles were changed from passive knowledge recipients to active classroom participants through various forms such as classroom discussions and case studies, yet the above forms of teaching were still limited to the knowledge framework of single curriculum. Now, the construction of the curriculum group integrates the originally fragmented management knowledge that students can integrate knowledge from different subjects and different curricula and play a new role in refining knowledge, summarizing knowledge, and creating knowledge and actively grow up as knowledge sharers and contributors.

\section{The TheORETICAL ANALYsis of CONSTRUCTING Hotel MANAGEMENT CURRICUlum GROUP}

\section{A. Cross-Subject: The feasibility of constructing hotel management curriculum group}

Hotel management, a product of management, economics, psychology, hotel operations and other subjects is a comprehensive cross-subject. With the rich in the subject content and the changes in the hotel industry practice, the education and teaching reform of hotel management has been ongoing. From the one hand, the characteristic of cross-subject in hotel management is reflected in the continuous infiltration of basic curricula such as management, economics, psychology and others, which not only enhances the theoretical height of the hotel management curriculum group, but also expands the teaching content of the hotel management curriculum group. On the other hand, it is reflected in the connection between different professional curricula such as hotel management, hotel reception and room management, hotel catering management, hotel marketing, hotel financial management, and hotel human resource management. Therefore, based on the concept of integration to analyze the relationship of bachelor curriculum group for hotel management, it is feasible to construct the bachelor curriculum group for hotel management.

As a cross-subject, the knowledge structure of hotel management is relatively complex, which resulting in different perceptions by teaching administrators, teachers, students, and parents in different colleges and universities. The reason is that although hundreds of colleges and universities set this majors, the curricula offered by each institution are very different. It is said that the recognition and recognition of majors not only depend on professional orientation, but also depend more on whether or not students can acquire a wide range of knowledge and comprehensive capabilities through an integrated, systematic curriculum framework and knowledge system. Therefore, the major of hotel management needs to build a curriculum group to strengthen the curriculum relationship and establish a curriculum system that reflects the core competence of the profession and meets the goal of talent cultivation.

\section{B. Cultivating talents: The purpose of constructing hotel management curriculum group}

Currently, the major of hotel management has formed a multilevel system of talent cultivation from associate degree, bachelor degree, master degree, even to doctoral degree. It can be said the realization of the goal of applied talents cultivation is inseparable from the curriculum system setting. As far as the undergraduate education of hotel management is concerned, the core goal of talent cultivation is to cultivate the high-quality applied talents with strong practical ability, employ ability, entrepreneurial ability and innovation ability, which also have modern professional qualities and international perspectives, systematically master the basic theories, knowledge, and skills in hotel development, operations, supervision, and management, and can use hotel management theories to comprehensively analyze and solve problems in the hotel management. Therefore, how to train applied talents through curriculum reforms to meet the demands of modern hotel industry and local economic development is a prominent issue facing the major of hotel management.

The scope of employment for hotel management students has become extensive, from the traditional accommodation reception industry to the modern service industry, and the rationalization of curriculum setting is of great significance for cultivating talents hotel management, which exactly conforms to the needs of the in-depth reform of the hotel management curriculum. It in accordance with the student's learning requirements and the characteristics of the subject itself, optimizing the relationship between relevant curricula and building a more scientific and efficient curriculum system which will help students develop a model of open thinking and 
a comprehensive ability to identify problems, analyze problems and solve problems.

\section{The reflection of the status: The urgency of constructing hotel management curriculum group}

Most of the domestic colleges and universities in the major of hotel management curricula are based on the core curricula to establish a horizontal curriculum system, which cannot fully meet the demand of the hotel industry, and there are some problems in the curriculum system. For example, some contents appear in many curricula, but the industry trend stemming from changes in practice and the frontier theory originating from the development of subjects do not appear in the curriculum system in time; the Principles of Management, Hotel Management, Hotel Reception and Room Management, and other closely related curricula are not established on the same standard of content; the internship and experiments in the hotel reception and room management, hotel marketing and other curriculum are relatively independent, while there is no comprehensive application of internships and experiments among multiple curricula, which results in the waste of teaching resources; in the teaching evaluation mechanism, the closed-book examinations of various curricula are still the main evaluation method which can neither accurately reflect the teaching effect and teaching quality, nor can it accurately test the comprehensive ability and quality of student ${ }^{[5]}$. It can be said that the above problems are impelling the reform of hotel management courses.

According to the optimization theory, the sum of local optimization does not equal to the overall optimization, and even local optimization may damage the overall optimization. Therefore, it is not possible to start a partial curriculum reform from single curriculum, but rather to develop the hotel management curriculum group from overall perspective. In the teaching process, the repetition content between curricula is removed, and different curricula are used to learn from each other in terms of teaching objectives, teaching contents, teaching models, teaching evaluation and so on, and the effectiveness of teaching is improved at a higher level; besides, it can guide students to clarify their own learning goals, integrate knowledge from different curricula, and integrate knowledge and practice so as to improve the efficiency of curriculum learning.

\section{The Practice PATH of Constructing Hotel MANAGEMENT CURRICULUM GROUP}

\section{A. Use co-evolution theory, reconstruct curriculum content}

The Co-evolution refers to the fact that a curriculum affects other curricula through its own evolution, and the evolution of other curricula changes the evolution of this kind of curriculum and eventually leads to the evolution of the entire curriculum system ${ }^{[6]}$. It includes two meanings: the first is the synergy between the internal elements of the curriculum group, which promotes the promotion of a single curriculum group; the second is the interaction between the curriculum groups to achieve the development of multiple curriculum groups. Moreover, the construction of the curriculum group under the guidance of co-evolution theory not only considers the structure and content of its own curriculum system, but needs to coordinate well the contents of different curricula and clarify the differences and logical relationships between them. Therefore, the reasonable design of curriculum themes, the strengthening of the links between different subjects, and the reconstruction of the curriculum content have become the basis work for building a hotel management curriculum group.

The example, the curriculum of Introduction to Hotel Management is combined with other related curricula to build from the curriculum of subject principle (Principle of Management and Western Economics), the professional basic curriculum (Introduction to Hotel Management), professional knowledge and capability curriculum of (Hotel Front office and Room Management, Hotel food and beverage management, Hotel Marketing and Hotel Financial Management, etc.) to professionalism quality curriculum (Beverage Management, Tea Art and Flower Arrangement), which can form the relationship of co-evolution in relevant curriculum(Fig.1.). In the specific implementation, firstly, the curriculum which the teachers are responsible should make plans with the outline and design guide for the curriculum of Hotel Management, and then the teachers of the related subjects jointly screen the curriculum contents. Finally, after collective discussion, they modify, improve and form the final integrated curriculum program. On this basis, the college may establish several teams with integrated curriculum development in the curriculum group, which can integrate the teachers' resources in the college or other colleges, and based on repeated argumentation and multiple opinions, reasonably determine the curriculum content of different subjects in the curriculum group so as to develop corresponding teaching courseware and other course materials.

\section{B. Strengthen team consciousness; cultivate cross-subject teaching quality}

Under the framework of constructing curriculum group, teachers are given more tasks and missions. The breadth and depth of teachers' knowledge directly determines whether "speak generally" or "speak universally" during the teaching process. In order to strengthen the ability to dominate the teaching content of hotel management curriculum group, the teaching process in the curriculum requires teachers to enhance the team-oriented teaching consciousness, participate in teaching activities in the form of teamwork, and share the frontiers and dynamics of subject development in their respective fields. On the basis of strengthening the teaching skills of main subject, teachers should explore the connection points of knowledge; expand into related subjects with divergent thinking, which can make them become the versatile educational talents. 


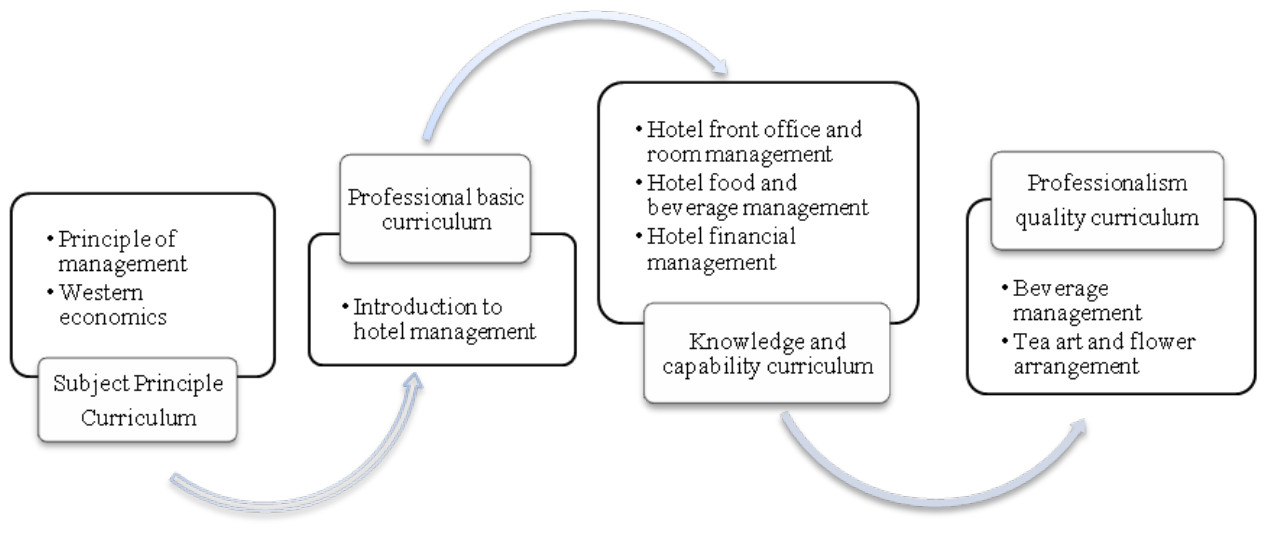

Fig. 1. Curriculum group of hotel management

The cooperative form of the teaching team in the curriculum group can be divided into two forms: The first is the cooperative teaching based on knowledge structure. Teachers with different curriculum backgrounds can collaborate to set up curricula that they can interpret the problems from the perspective of their own subjects in the classroom, and present to students with different perspectives as well as rich and varied views. The second is the cooperative teaching based on teaching methods. The implementation of teaching in the curriculum group requires theoretical knowledge, practical experience, and various technical means to cooperate with each other. Besides, a variety of teaching links give opportunities for teachers with different teaching styles to cooperate.

\section{Establish the learning mode that contains both learning and thinking}

The form in the curriculum group has been given more changes that students are often required to participate in classroom teaching with an active and positive attitude during the learning process, break the convention of "passive participation", and regard themselves as knowledge sharers and contributors. At the same time, students integrate the knowledge from different curricula in the curriculum group and gradually establish their own knowledge system. Faced with the myriads of changes of realities in hotel management, students can effectively apply knowledge to management practices and actively consider various management issues that can possibly occur, management decisions, and the management results. Studying with this kind of learning model can help student deepen the understanding of hotel management theories, knowledge and methods, and consolidate the effects of learning in curriculum.

\section{SUMMARY}

The development of hotel industry and the education of hotel management has put forward new requirements for the construction of hotel management curriculum group with the connection of logical links among curricula, aiming at cultivating students' comprehensive management capacities, and supported by the teaching team's cooperation is an effective approach for curriculum teaching reform.. According to the meaning and function of the curriculum group and based on the characteristics of cross-subject in hotel management, the target of cultivating talents and the refection of current teaching status, the essay has analyzed the feasibility, purpose and urgency of the current construction in hotel management curriculum group, and put forward practical paths for the construction of hotel management curriculum group from three aspects including the reconstruction of curriculum content, the cultivation of curriculum team with cross-subject teaching quality and the guidance of students to establish the learning mode that contains both learning and thinking.

\section{REFERENCES}

[1] Zhao Huichen, He Qi,“The Theory Discussion and Practice about Curriculum Group Construction in Educational Technology Undergraduate”. Modern Educational Technology. vol.23, pp.64-69. February 2013.(In Chinese)

[2] Long Chunyang. "Curriculum Group Construction: The Path Choice of University Curriculum Teaching Reform”. Modern Education Science. vol.33, pp.139-141. February 2010. (In Chinese)

[3] Liu Gang, Yu Xiaodong, Cheng Xirong. "Integrated Curriculum and Its Application in Management Education". China Higher Education Research. vol9, pp.84-88. September 2015.(In Chinese)

[4] Liu Gang, Lv Wenjing. "Reflective Teaching and Its Application in Management Education”. China Higher Education Research. vol9, pp.105-110. March 2014.(In Chinese)

[5] Jiang Shengmei, $\mathrm{Hu}$ Xiuhong. "Analysis of interdisciplinary undergraduate education in the United States". Information on Education. Vo12, pp.23-25. October 2015.(In Chinese)

[6] Zhao Huichen, "Commentary on co-evolution of curriculum group". Modern Education Management. Vo12, pp.105-108. December 2012.(In Chinese) 